\title{
Factors associated with emergency department length of stay of internal medicine patients
}

\author{
Sanne Vonk, ${ }^{1}$ Jaap Leermakers, ${ }^{2}$ Susan J.J. Logtenberg, ${ }^{3}$ Sanjay U.C. Sankatsing ${ }^{3}$ \\ ${ }^{1}$ Department of Nephrology and Hypertension, University Medical Center Utrecht, Utrecht; ${ }^{2}$ Department of \\ Facility and Logistics, Diakonessenhuis, Utrecht; ${ }^{3}$ Department of Internal Medicine, Diakonessenhuis, \\ Utrecht, the Netherlands
}

\begin{abstract}
Emergency Department (ED) Length Of Stay (ED-LOS) is associated with quality of care, patient safety and treatment outcome. The aim of this study is to identify factors associated with ED-LOS of internal medicine patients and provide recommendations to shorten ED-LOS. A retrospective cohort study was conducted in a single center in the Netherlands. Anonymised data of 7,380 ED attendances from January 2016 to January 2018 were analyzed. Data included time of ED arrival and departure, sex, age, source of referral, triage category, first or consecutive visit and number of radiological examinations. Univariate analyses were used. Mean ED-LOS was 220 minutes. Factors which significantly
\end{abstract}

Correspondence: Sanne Vonk, Department of Nephrology and Hypertension, University Medical Center Utrecht, House post number F03.223, P.O. box 85500, 3508 GA Utrecht, The Netherlands.

Tel.: +31.88.7555555 - Fax: +31.88.7556283

E-mail: s.vonk-6@umcutrecht.nl

Key words: Emergency department; influencing factors; length of stay; urban teaching hospital; quality of care.

Contributions: SL and SS designed the study, SV and JL designed the computational framework and analyzed the data, SV wrote the manuscript with support from SL and SS, all authors discussed the results and contributed to the final manuscript.

Conflict of interest: None. This work was not supported by any grant.

Availability of data and materials: The data that support the findings of this study are available from the corresponding author, SV, upon reasonable request.

Ethics approval and consent to participate: This analysis was done as part of a quality of care evaluation using anonymized patient data, therefore was without the need for patient informed consent.

Consent for publication: Not applicable.

Received for publication: 22 December 2020.

Revision received: 9 April 2021.

Accepted for publication: 30 April 2021.

This work is licensed under a Creative Commons Attribution 4.0 License (by-nc 4.0).

(Copyright: the Author(s), 2021

Licensee PAGEPress, Italy

Emergency Care Journal 2021; 17:9570

doi:10.4081/ecj.2021.9570 prolonged ED-LOS were older age, source of referral, triage category, need for admission, first visit, number of radiological examinations, presentation in winter or spring and time of arrival (day and evening). Several patient and circumstantial factors are associated with ED-LOS. To shorten ED-LOS, we recommend to anticipate need for admission for older patients who arrive by ambulance and to create time slots in the radiology program and to restructure the morning report.

\section{Introduction}

The time a patient spends at the Emergency Department (ED) has become an increasingly discussed quality measure, since prolonged ED Length Of Stay (ED-LOS) is associated with reduced patient satisfaction, prolonged hospital stay, increased mortality, increased number of patients leaving without consultation with an ED physician and higher healthcare costs..$^{1-8}$ Moreover, prolonged ED-LOS leads to crowding, which occurs when the need for emergency services exceeds available resources at the ED. Prolonged ED-LOS can also be the result of crowding, yielding a vicious cycle. ${ }^{9}$

It is worthwhile to elucidate the determinants of ED-LOS and identify possible modifiable factors to eventually improve quality of care. Previous studies have described many factors responsible for ED-LOS, including patient related factors such as age and ethnicity; process related factors such as diagnostics, consultation, source of referral, triage category and need for admittance; hospital related factors such as staff occupation, seniority physician and bed occupancy at the clinical wards, Intensive Care and the ED; and time related variables such as season, day of the week and time of arrival..$^{510-21}$ Vegting, Alam et al. and Vegting, Nanayakkara et al. demonstrated in a study in 2 hospitals in the Netherlands that patients referred to the internal medicine department were most likely to exceed a four-hour target of ED-LOS compared to other medical specialties. ${ }^{17,18}$

The primary objective of this study is to identify factors that are associated with longer ED-LOS of internal medicine patients. The second objective is to provide recommendations to shorten ED-LOS for this patient category.

\section{Materials and Methods}

\section{Study design and participants}

A retrospective cohort study was conducted at the Diakonessenhuis Utrecht. The study population consisted of all patients seen by internal medicine physicians at the ED of the Diakonessenhuis between January $1^{\text {st }}, 2016$ and December $31^{\text {st }}$, 2017. 


\section{Hospital setting}

The Diakonessenhuis Utrecht is a 500-bed urban non-academic teaching hospital in the Netherlands. It is a hub and has a spoke situated in the city of Zeist (at approximately $13 \mathrm{~km}$ distance) and the city of Doorn (approximately $24 \mathrm{~km}$ distance). Annually, there are approximately 23,500 day care admittances, 22,000 admittances lasting longer than one day and 390,000 outpatient clinic visits. The ED is situated at the Utrecht location. The catchment area of the Diakonessenhuis consists of the city of Utrecht (approximately 360,000 inhabitants) and the Utrecht province (approximately 733,000 inhabitants). Two other hospitals are situated in the city of Utrecht; both tertiary referral hospitals; one academic (University Medical Center Utrecht, 1000 beds) and one non-academic (St. Antonius hospital, 850 beds).

The ED of the Diakonessenhuis is utilized to treat patients with a wide range of pathology, except for multi trauma patients and patients suspected to have an acute coronary syndrome needing emergency coronary intervention. Those patients are referred to the ED of the other city hospitals. The internal medicine physicians in particular see the entire spectrum of the internal medicine plus gastroenterology and geriatrics, aside from patients with stem cell transplants and kidney transplants in the first year of follow-up. Each year there are approximately 25,000-26,000 visits to the Diakonessenhuis ED of which $14-15 \%$ is registered for the internal medicine department.

At the Diakonessenhuis, internal medicine patients (from now on referred to as patients) are cared for in the ED by an internal medicine resident (trainee and non-trainee) who is supervised by an internist. During office hours ( 8 a.m. until 5 p.m.), this supervisor is present in the hospital. Outside office hours, the internist is available on-call. The day shift starts with one resident who is present from 8 a.m. until 5 p.m. At 11 a.m., a second resident starts who is present until 8 p.m. At 5 p.m., the evening shift begins with two residents present until 11 p.m. One resident is present from 11 p.m. until 8 a.m. An Emergency Physician is always present for consultation and coordination.

\section{Data collection}

Data were anonymously extracted from the hospital registration system. Data included date and time of ED arrival and departure, sex, age, source of referral, triage category, presenting complaint, destination, first or consecutive visits and number of radiological examinations. The first author (SV) validated the database. Reasons for exclusion of ED records were missing values, outliers, duplicates or patient age $<18$ years. Missing values were patient records where the data and time of ED arrival or departure were not registered. Outliers were defined as records with an ED-LOS of less than 25 or more than 1,200 minutes (cut-offs were determined after consensus between SV, SL and SS). Duplicates were identified as records of patients having two ED visits within less than 3 hours with the same presenting complaint.

This analysis was done as part of a quality of care evaluation using anonymized patient data, therefore was without the need for patient informed consent.

\section{Definitions}

ED-LOS was defined as the time interval in minutes between patient arrival at the ED and patient departure (either discharge or admission). Source of referral had 4 categories; free call (patient arriving by ambulance after calling the alarm number); referral by the General Practitioner (GP) by ambulance, referral by the GP with own transportation and other (the radiology department, selfreferral, outpatient clinic, another hospital, another specialty, nurs- ing home or consecutive visit). A consecutive visit was defined as a patient visiting the ED within 48 hours with the same presenting complaint. The Dutch Triage Standard was used for triage. ${ }^{22}$ Urgency levels (U) were classified as U0 (resuscitation), U1 (lifethreatening), U2 (emergent), U3 (urgent), U4 (non-urgent) and U5 (self-care advice). ED nurses register the triage category. The triage category is missing whenever crowding prevents the ED nurse from adequately registering the triage category because priority is given to direct patient care instead of these administrative tasks. Since missing values concerning triage category are situation related and not patient related, data from these patients is used in subgroup analyses not concerning triage category. Radiological examinations performed at the ED included X-rays, Computed Tomography (CT) scans, Magnetic Resonance Imaging (MRI) scans, ultrasounds and ventilation/perfusion lung scans. The destination of patients was either discharge, admission or other (mortuary, another institution or leaving before being treated). Patients were categorized into groups according to age, $<65$ years or $\geq 65$ years. Time of ED arrival was categorized into day ( 8 a.m. until 5 p.m.), evening (5 p.m. until midnight) and night (midnight till 8 a.m.).

\section{Statistical analysis}

Descriptive statistics [mean, Standard Deviation (SD)] were used to describe ED-LOS per factor. For the total population and for each subcategory separately, normal distribution with slight positive skewness was confirmed by visual inspection. Therefore, parametric tests were used. Univariate analysis was used to test the association of each factor with ED-LOS. A p-value $<0.05$ was considered statistically significant. Furthermore, independent sample t-tests for binary variables and one-way Analysis Of Variance (ANOVA) for categorical variables with multiple categories were used. If there was significance with ANOVA, post hoc analyses were used to determine significance relative to each other. Based on the assumption of (un)equal sample sizes or (un)equal group variances the post-hoc analyses were chosen (Tukey, Gabriel, Hochberg's GT2 or Games-Howell). ${ }^{23}$ The shortest ED-LOS was used as the reference group. An exception was made with the factor triage category. Since U0 (resuscitation) and U5 (self-care advice) are not representative of standard care, they were not eligible as a reference group. SPSS version 23.0 (IBM Corporation, Chicago, USA) was used for all analysis.

\section{Results}

\section{Overall population}

In 2016 and 2017 in total, 51,265 patients visited the ED of the Diakonessenhuis Utrecht. Of these, 7,613 visits (14.8\%) were registered for the internal medicine department of which 7,380 visits (96.9\%) were eligible for data analysis. Of these 7,380 visits, 3,580 were registered in 2016 and 3,800 in 2017. In total, 233 visits were excluded because of missing values $(n=13)$, outliers $(n=37)$, duplicates $(n=92)$ or age $<18$ years $(n=91)$. The mean age of patients was 59.2 years. There were slightly more females $(n=3,969,53.8 \%)$ than males $(n=3,411,46.2 \%)$. Most patients visited the ED on Friday $(\mathrm{n}=1,276,17.3 \%)$. Mean (SD) ED-LOS was 220.1 (93.0) minutes. Figure 1 shows the number of ED visits per 25-minute-duration groups with the solid line representing the cumulative percentage of ED-LOS. In Figure 2, both the number of patients and the mean EDLOS per hour of the day is shown. Most patients arrive at 4.00 p.m. The longest ED-LOS is observed at 7.00 a.m. 


\section{ED-LOS per factor}

Table 1 shows the ED-LOS per analysed factor. Patients older than 65 years stayed longer in the ED compared to younger patients; 236.5 (90.5) and 206.2 (92.9) minutes, respectively $(\mathrm{p}<0.001)$. Almost half of all patients were referred by their GP and came by own transportation. Fewest patients $(16.8 \%)$ came in as a free call. There was a significant association between the source of referral and the ED-LOS $(p<0.001)$. Patients who were referred by their GP and came by ambulance stayed the longest in the ED [242.7 (88.8) minutes]. Compared to patients referred by other sources, both types of GP referrals had a significant longer ED-LOS ( $<<0.001$ ), whereas free calls did not $(\mathrm{p}=0.12)$. Most patients were either given the triage category U2 $(n=2,455,36.5 \%)$ or $U 3(n=3,090,45.9 \%)$. There was also a group of patients $(\mathrm{n}=651)$ who were not given a triage category. There was an association between the triage category and the EDLOS $(p<0.001)$. Yet compared to the reference group U4, only U2 and U3 patients had a significantly longer ED-LOS $(\mathrm{p}<0.001)$. The destination of the patient and the ED-LOS were associated. Being admitted or going to another destination significantly caused a longer ED-LOS compared to being discharged $(p<0.001)$. In 84 cases $(1.1 \%)$ patients came back for a second visit with the same presenting complaint within 48 hours. These patients had a significantly shorter ED-LOS than first time visit patients [189.4 (119.4) and 220.5 (92.6) minutes, respectively; $\mathrm{p}<0.05]$. The mean ED-LOS significantly increased with increasing number of radiological examinations, ranging from 190.1 (85.6) minutes without any tests to 299.3 (100.7) minutes when two or more examinations were done.

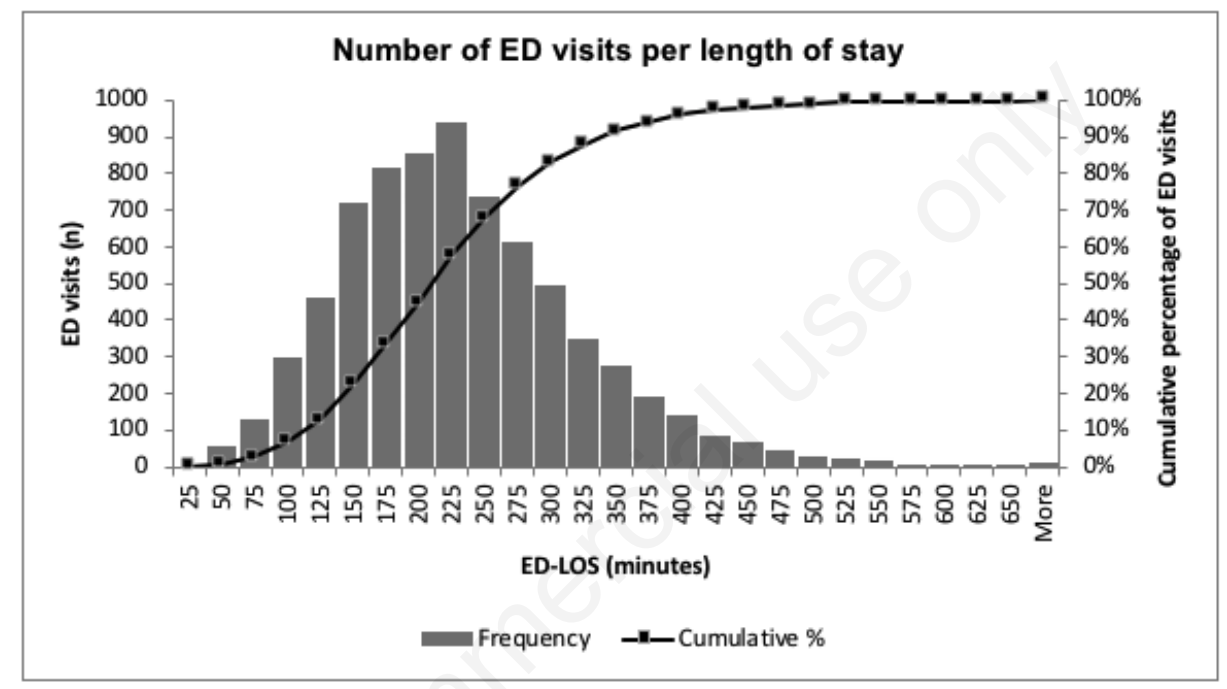

Figure 1. Number of ED visits per and cumulative percentage of length of stay. Legend: Bars represent the number of ED visits per length of stay (per 25 minute duration). The solid line represents the cumulative percentage of ED-LOS. ED: Emergency Department; LOS: Length Of Stay.

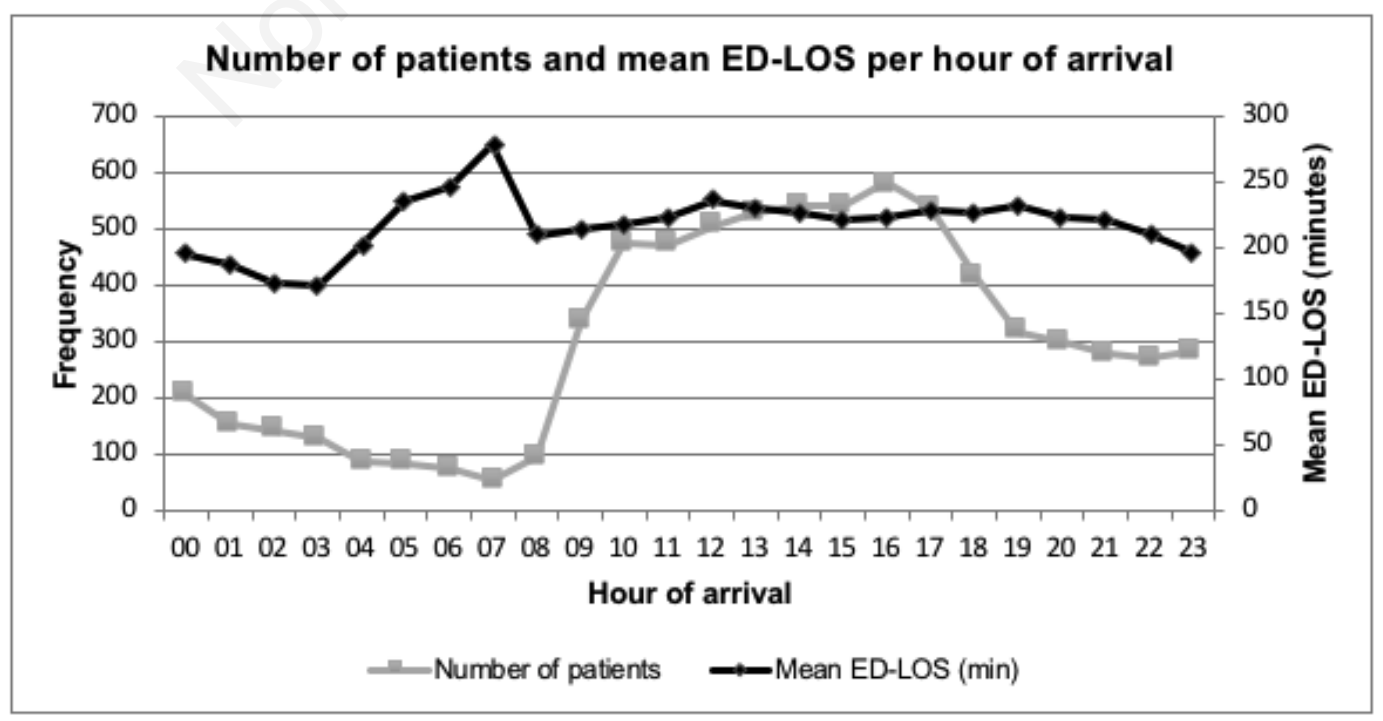

Figure 2. Number of patients and mean ED-LOS per hour of arrival. ED: Emergency Department; LOS: Length Of Stay. 
Visits were equally distributed over the 4 seasons. Yet, the mean EDLOS differed significantly between seasons. In summer, ED-LOS was the shortest [211.8 (92.7) minutes]. Compared to a summer visit, visiting in winter and spring significantly lengthened the EDstay [230.9 (93.9) and 221.1 (94.3) minutes, respectively; $\mathrm{p}<0.05$ ]. The ED-LOS did not significantly differ between males and females or days of the week. More than half of the patients arrived at the ED during the day $(\mathrm{n}=4,066,55.1 \%)$. Almost one third of the patients came in the evening $(n=2,394,32.4 \%)$. Arriving during the day or evening resulted in the same mean ED-LOS [224.2 (89.8 and 93.5) minutes), which was significantly longer compared to that of the night-arrivals [199.0 (100.0) minutes; $\mathrm{p}<0.05]$.

Table 1. ED-LOS of different groups of patients for the internal medicine department.

\begin{tabular}{|c|c|c|c|c|c|}
\hline \multirow[t]{2}{*}{ Factors } & \multirow[t]{2}{*}{ Number of patients } & \multirow[t]{2}{*}{$\%$} & \multicolumn{2}{|c|}{ ED-LOS (minutes) } & \multirow[t]{2}{*}{ p-value ${ }^{a}$} \\
\hline & & & Mean & SD & \\
\hline Total & 7,380 & 100 & 220.1 & 93.0 & \\
\hline $\begin{array}{ll}\text { Sex } & \\
- & \text { Male } \\
- & \text { Female }\end{array}$ & $\begin{array}{l}3,411 \\
3,969\end{array}$ & $\begin{array}{l}46.2 \\
53.8\end{array}$ & $\begin{array}{l}220.1 \\
220.1\end{array}$ & $\begin{array}{l}93.7 \\
92.5\end{array}$ & 0.996 \\
\hline $\begin{array}{l}\text { Age at ED arrival } \\
-\quad<65 \text { years } \\
-\quad \geq 65 \text { years }\end{array}$ & $\begin{array}{l}3,992 \\
3,388\end{array}$ & $\begin{array}{l}54.1 \\
45.9\end{array}$ & $\begin{array}{l}206.2 \\
236.5\end{array}$ & $\begin{array}{l}92.9 \\
90.5\end{array}$ & $<0.001$ \\
\hline $\begin{array}{ll}\text { Source of referral } \\
\text { - } & \text { Free call (112) } \\
\text { - } & \text { GP - ambulance } \\
\text { - } & \text { GP - own transport } \\
\text { - } & \text { Other } \\
\end{array}$ & $\begin{array}{l}1,238 \\
1,783 \\
3,063 \\
1,296 \\
\end{array}$ & $\begin{array}{l}16.8 \\
24.2 \\
41.5 \\
17.5\end{array}$ & $\begin{array}{l}204.0 \\
242.7 \\
224.0 \\
195.2\end{array}$ & $\begin{array}{l}103.2 \\
88.8 \\
85.8 \\
96.4\end{array}$ & $\begin{array}{c}<0.001 \\
0.124 \\
<0.001 \\
<0.001 \\
\text { Reference }\end{array}$ \\
\hline \begin{tabular}{ll}
\multicolumn{2}{l}{ Triage category } \\
- & U0 - Resuscitation \\
- & U1 - Life-threatening \\
- & U2 - Emergent \\
- & U3 - Urgent \\
- & U4 - Non-urgent \\
- & U5 - Self-care advice
\end{tabular} & $\begin{array}{c}6 \\
392 \\
2,455 \\
3,090 \\
768 \\
18^{c}\end{array}$ & $\begin{array}{c}0.1 \\
5.8 \\
36.5 \\
45.9 \\
11.4 \\
0.3\end{array}$ & $\begin{array}{l}142.7 \\
213.0 \\
230.2 \\
224.7 \\
201.8 \\
178.2\end{array}$ & $\begin{array}{l}61.6 \\
99.0 \\
96.2 \\
88.9 \\
91.7 \\
82.1\end{array}$ & $\begin{array}{c}<0.001 \\
0.850 \\
0.539 \\
<0.001 \\
<0.001 \\
\text { Reference } \\
0.993\end{array}$ \\
\hline $\begin{array}{ll}\text { Destination } \\
\text { - } & \text { Discharge } \\
\text { - } & \text { Admission } \\
\text { - } & \text { Other }^{\mathrm{d}} \\
\end{array}$ & $\begin{array}{c}3,241 \\
4,081 \\
58\end{array}$ & $\begin{array}{c}43.9 \\
55.3 \\
0.8 \\
\end{array}$ & $\begin{array}{l}191.3 \\
241.9 \\
296.0\end{array}$ & $\begin{array}{c}87.7 \\
89.9 \\
129.3 \\
\end{array}$ & $\begin{array}{c}<0.001 \\
\text { Reference } \\
<0.001 \\
<0.001\end{array}$ \\
\hline $\begin{array}{l}\text { Visit } \\
\text { - } \quad \text { First visit } \\
\text { - }\end{array}$ & $\begin{array}{c}7,296 \\
84\end{array}$ & $\begin{array}{c}98.9 \\
1.1\end{array}$ & $\begin{array}{l}220.5 \\
189.4\end{array}$ & $\begin{array}{c}92.6 \\
119.4\end{array}$ & $<0.05$ \\
\hline $\begin{array}{l}\text { Radiological examinations } \\
\text { - } \quad \text { No.0 } \\
\text { - } \quad \text { No.1 } \\
\text { - } \quad N_{0 .} \geq 2^{\mathrm{f}}\end{array}$ & $\begin{array}{c}3,351 \\
3,115 \\
914 \\
\end{array}$ & $\begin{array}{l}45.4 \\
42.2 \\
12.4 \\
\end{array}$ & $\begin{array}{l}190.1 \\
229.2 \\
299.3 \\
\end{array}$ & $\begin{array}{c}85.6 \\
82.2 \\
100.7 \\
\end{array}$ & $\begin{array}{c}<0.001 \\
\text { Reference } \\
<0.001 \\
<0.001\end{array}$ \\
\hline \begin{tabular}{ll}
\multicolumn{2}{l}{ Season } \\
- & Winter \\
- & Spring \\
- & Summer \\
- & Autumn
\end{tabular} & $\begin{array}{l}1,806 \\
1,843 \\
1,834 \\
1,897\end{array}$ & $\begin{array}{l}24.5 \\
25.0 \\
24.8 \\
25.7\end{array}$ & $\begin{array}{l}230.9 \\
221.2 \\
211.8 \\
216.9\end{array}$ & $\begin{array}{l}93.9 \\
94.3 \\
92.7 \\
93.0\end{array}$ & $\begin{array}{c}<0.001 \\
<0.001 \\
<0.05 \\
\text { Reference } \\
\quad 0.339\end{array}$ \\
\hline $\begin{array}{ll}\text { Day of the week } \\
\text { - } & \text { Monday } \\
\text { - } & \text { Tuesday } \\
\text { - } & \text { Wednesday } \\
\text { - } & \text { Thursday } \\
\text { - } & \text { Saturday } \\
\text { - } & \text { Sunday } \\
\end{array}$ & $\begin{array}{c}1,131 \\
970 \\
1,025 \\
1,074 \\
1,276 \\
960 \\
944\end{array}$ & $\begin{array}{l}15.3 \\
13.1 \\
13.9 \\
14.6 \\
17.3 \\
13.0 \\
12.8\end{array}$ & $\begin{array}{l}222.6 \\
225.7 \\
217.5 \\
218.3 \\
220.4 \\
222.1 \\
213.7\end{array}$ & $\begin{array}{l}95.2 \\
93.4 \\
88.7 \\
93.4 \\
88.1 \\
95.1 \\
98.1\end{array}$ & 0.104 \\
\hline \begin{tabular}{ll}
\multicolumn{2}{l}{ Time of arrival } \\
- $\quad$ Day (8 a.m. till 5 p.m.) \\
- $\quad$ Evening ( 5 p.m. till midnight) \\
- $\quad$ Night (midnight till 8 a.m.)
\end{tabular} & $\begin{array}{c}4,066 \\
2,394 \\
920\end{array}$ & $\begin{array}{l}55.1 \\
32.4 \\
12.5\end{array}$ & $\begin{array}{l}224.2 \\
224.2 \\
199.0 \\
\end{array}$ & $\begin{array}{c}89.8 \\
93.5 \\
100.0 \\
\end{array}$ & $\begin{array}{c}<0.001 \\
<0.05 \\
<0.05 \\
\text { Reference }\end{array}$ \\
\hline
\end{tabular}

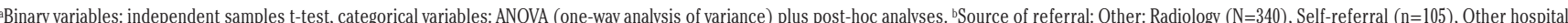
$(\mathrm{n}=17)$, Other specialty ( $\mathrm{n}=52)$, Nursing home $(\mathrm{n}=46)$, Outpatient clinic of the internist ( $\mathrm{n}=536)$, Residency Diakonessenhuis Zeist ( $\mathrm{n}=33$ ), Consecutive visit ( $\mathrm{n}=84$ ), Control patient ( $\mathrm{n}=83$ ). ${ }^{\mathrm{C}}$ Adds up to 6,729 , instead of 7,380, since $n=651$ were not categorised and excluded from this subgroup analysis. ${ }^{d}$ Destination: Other: Mortuary $(n=7)$, Leaving without being seen ( $\mathrm{n}=2$ ), Other institution ( $\mathrm{n}=48$ ), Missing value ( $\mathrm{n}=1$ ). ${ }^{e}$ Consecutive visit: a patient visiting the ED within 48 hours with the same presenting complaint. 'Radiological examinations: $\geq 2$, maximum number of radiological examinations is 8 ( $\mathrm{n}=2$ ). ${ }^{\mathrm{g} S}$ Season: Winter is January until March, Spring: April until June, Summer: July until September, Autumn: October until December. ED: Emergency Department; GP: general practitioner; LOS Length Of Stay. 


\section{Other findings}

Of patients over 65 years of age, $71.2 \%$ was admitted to the hospital, in contrast to $41.8 \%$ of patients under 65 years of age. Patients who were referred by their GP and came by ambulance had the highest admittance percentage $(83 \%)$. Of all returning patients, $46.4 \%(\mathrm{n}=39)$ were admitted at the second visit.

\section{Discussion}

We investigated factors influencing ED-LOS for internal medicine department patients and found that patient's age, source of referral, triage category, discharge destination, first or consecutive $\mathrm{ED}$ visit, number of radiological examinations, season and time of arrival were significantly associated with ED-LOS, and that sex and presenting day of the week were not.

Mean ED-LOS in our study was 220 minutes, which is longer than in previous reports from other Dutch hospitals (120-170 minutes). ${ }^{16-18,24}$ One explanation might be that previous studies included patients at the ED for all specialties, and not only internal medicine patients. Compared to international data on ED-LOS, varying from 160 to 440 minutes, our ED-LOS was relatively short. ${ }^{5,14,20,25}$ Our results regarding sex, age and radiological examinations are in accordance with previous findings. ${ }^{10-19,26}$ Brouns et $a l$. specifically investigated the effect of age of internal medicine patients and demonstrated that the ED-LOS is considerably longer (30 minutes) in elderly patients ( $\geq 65$ years). ${ }^{13}$ Multiple studies show that the kind of radiological examination also influences the ED-LOS, where patients receiving CT, MRI or ultrasound investigations stay longer in the ED compared to patients receiving only conventional X-rays. ${ }^{10,14,17-19}$

The group of patients referred by their GP and arriving by ambulance stays the longest in the ED and has the highest admittance percentage. Inconsistency is noticed in literature, where source of referral either does not affect ED-LOS, ${ }^{12,15,26}$ self-referred patients and patients referred by radiology significantly shorten the ED-LOS ${ }^{11,13,16}$ or patient arrival by ambulance significantly prolong ED-LOS. 13,19

Most patients were triaged as category U2 and U3 and showed significantly prolonged ED-LOS. U1 patients should be seen within 10 minutes and therefore have no waiting time. U4 patients are classified not urgent with a presenting complaint deemed not severe, which probably means they can be handled fast and therefore can leave the ED sooner. ${ }^{13,17,19}$

We found that being admitted prolongs ED-LOS in comparison to being discharged. Bed occupancy in clinical wards causes patients having to wait in the ED before being admitted. ${ }^{27,28}$ Administrative procedures, such as prescribing medication, writing admittance letters and recording assignments to nurses take extra time. If patients are transferred to another institution, EDLOS is even longer. Both arranging transportation and a bed elsewhere takes time.

We assumed that more patients would visit the ED in winter and spring, because of the influenza epidemic during these seasons in 2016 and 2017. Remarkably, however, the number of visits was equal for all seasons. The ED-LOS did vary though, with the longest being observed in winter, followed by spring. This might still be explained by the influenza season, since patients with chronic lung diseases, who are more prone to influenza complications, ${ }^{29}$ might have visited the Pulmonology ED, at higher frequencies and thereby occupying general ED resources. Our data only concerns internal medicine patients and therefore we do not know the total number of ED visits per day.

Most patients visited the ED on Monday and Friday. Probably, because in the Netherlands the GP refers the patient to the ED for further examination and because patients prefer consulting their own GP, who is available on weekdays only. Nonetheless, the EDLOS did not significantly change with day of the week, which is comparable to the findings of Vegting et al. ${ }^{17}$

The same trend seems to occur for time of arrival. The frequency of patients arriving at the ED peaks at 4 p.m. at the end of the GP's consultation hours, yet the ED-LOS remains globally the same. This might be explained by having more residents on the floor between 4 and 8 p.m. Patients stay the longest in the ED if they arrive at $7 \mathrm{a}$ a.m. We speculate that this is because the resident on night duty only assesses whether the patient is stable enough to be seen later and that regular consultation is only started after the 8 a.m. report by the daytime resident.

Vegting et al. and Bucheli et al. reported that ED-LOS was significantly reduced if the supervisor was present in the hospital until 11 p.m. ${ }^{17,30}$ Our data does not support this. On the contrary, in our study ED-LOS is the shortest during the night and the same during day and evening. The supervisor is only physically present during the day. Our mean ED-LOS during the night is shorter despite having less residents available, yet the visit frequency is also far less. A possible explanation for this finding might be that because of fewer admissions in the night there is less delay in transportation of the patient to the ward.

In 2012 van der Linden et al. conducted a survey among ED nurse managers $(\mathrm{n}=62)$ from 63 EDs in the Netherlands about crowding. Respondents cited consultation, radiology and laboratory tests and hospital bed shortage as the 3 most important reasons for crowding..$^{24}$ We did not investigate the effect of consultations and hospital bed shortage on ED-LOS in our study, but this assumption is confirmed by previous studies. $12,13,17,18,20,21$

There are some limitations to our study. We used data from a single urban non-academic teaching hospital in the Netherlands and included data from internal medicine patients only, which may limit generalizability. Furthermore, our database contained routinely collected data, thereby lacking information regarding number of consultations, bed occupancy rate, the seniority of the attending physician and detailed information regarding the radiological examination ordered. Moreover, when validating the database, it became known that subprocesses -such as waiting room time, triage time, treatment time and waiting time for admission- were inaccurately registered. This made it impossible to distinguish which subprocesses had the biggest influence on EDLOS. Lastly, since we primarily focused on identifying factors affecting ED-LOS, a multivariate analysis was not performed. Therefore, we cannot conclude about the relationship between these factors.

\section{Recommendations}

Based on our results we do the following recommendations to EDs with a comparable organization and capacity as Diakonessenhuis Utrecht; at the registration of a patient aged $\geq 65$ years arriving by ambulance the clinical ward coordinator is already asked to arrange the admittance of the patient.

Furthermore, because ED-LOS significantly increased with increasing number of radiological examinations and literature supports that longest ED-LOS is found with CT and MRI scans, it would be beneficial to create time slots in the radiology program 
specifically for emergency CT and MRI scans. First, more detailed information regarding the number of emergency scans per day and week is needed in order to plan this most efficiently. Besides that, because the longest ED-LOS occurs at 7 a.m., the morning report should be reorganised, so that the ED patient is attended to immediately. Because of the small number of patients, presenting at this hour, this intervention will not have great impact on the overall ED-LOS. Lastly, accurate registration of the time the subprocesses at the ED take can facilitate studying their impact on ED-LOS and possibly identify subprocesses requiring interventions.

\section{Conclusions}

Patient's age, source of referral, triage category, discharge destination, first or consecutive ED visit, number of radiological examinations, season and time of arrival are significantly associated with ED-LOS. Based on these findings, we recommend several actions be generated to shorten ED-LOS. For instance, early contact with the clinical ward coordinator for patients $>65$ years who arrive by ambulance, creating time slots in the radiology program and restructuring the morning report.

\section{References}

1. Taylor C, Benger JR. Patient satisfaction in emergency medicine. Emerg Med J 2004;21:528-32

2. Singer AJ, Thode HC, Viccellio P, Pines JM. The association between length of emergency department boarding and mortality. Acad Emerg Med 2011;18:1324-9

3. Liew D, Liew D, Kennedy MP. Emergency department length of stay independently predicts excess inpatient length of stay. Med J Australia 2003;179:524-6.

4. Hobbs D, Kunzman SC, Tandberg D, Sklar D. Hospital factors associated with emergency center patients leaving without being seen. Am J Emerg Med 2000;18:767-72.

5. Bashkin O, Caspi S, Haligoa R, et al. Organizational factors affecting length of stay in the emergency department: Initial observational study. Isr J Health Policy 2015;4:38.

6. Falvo T, Grove L, Stachura R, et al. The opportunity loss of boarding admitted patients in the emergency department. Acad Emerg Med 2007;14:332-7.

7. Foley M, Kifaieh N, Mallon WK. Financial impact of emergency department crowding. West J Emerg Med 2011;12:1927.

8. Schreyer K, Martin R. The economics of an admissions holding unit. West J Emerg Med 2017;18:553-8.

9. McCarthy ML, Zeger SL, Ding R, et al. Crowding delays treatment and lengthens emergency department length of stay, even among high-acuity patients. Ann Emerg Med 2009;54:492503.

10. Banerjea K, Carter AO. Waiting and interaction times for patients in a developing country accident and emergency department. Emerg Med J 2006;23:286-90.

11. Bobrovitz N, Lasserson DS, Briggs ADM. Who breaches the four-hour emergency department wait time target? A retrospective analysis of 374,000 emergency department attendances between 2008 and 2013 at a type 1 emergency department in England. BMC Emerg Med 2017;17:32.

12. Brick C, Lowes J, Lovstrom L, et al. The impact of consultation on length of stay in tertiary care emergency departments.
Emerg Med J 2014;31:134-8.

13. Brouns SHA, Stassen PM, Lambooij SLE et al. Organisational factors induce prolonged emergency department length of stay in elderly patients - A retrospective cohort study. PLOS One 2015; 10:e0135066.

14. Gardner RL, Sarkar U, Maselli JH, Gonzales R. Factors associated with longer ED lengths of stay. Am J Emerg Med 2007;25:643-50.

15. Hosseininejad SM, Aminiahidashti H, Pashaei SM, et al. Determinants of prolonged length of stay in the emergency department; a cross-sectional Study. Emergency 2017;5:e53.

16. Thijssen WAMH, Kraaijvanger N, Barten DG, et al. Impact of a well-developed primary care system on the length of stay in emergency departments in the Netherlands: A multicenter study. BMC Health Serv Res 2016;16:149.

17. Vegting IL, Alam N, Ghanes K, et al. What are we waiting for? Factors influencing completion times in an academic and peripheral emergency department. Neth J Med 2015;73:33140.

18. Vegting IL, Nanayakkara PWB, van Dongen AE, et al. Analysing completion times in an academic emergency department: Coordination of care is the weakest link. Neth J Med 2011;69:392-8

19. Casalino E, Wargon M, Peroziello A, et al. Predictive factors for longer length of stay in an emergency department: a prospective multicentre study evaluating the impact of age, patient's clinical acuity and complexity, and care pathways. Emerg Med J 2014;31:361-8.

20. Rathlev NK, Chessare J, Olshaker J, et al. Time series analysis of variables associated with daily mean emergency department length of stay. Ann Emerg Med 2007;49:265-71.

21. Hoot NR, Aronsky D. Systematic review of emergency department crowding: causes, effects, and solutions. Ann Emerg Med 2008;52:126-36.

22. Nederlandse Triage Standaard. Basisprincipes NTS. 2014. Accessed 2020 June 18. Available from: https://de-nts.nl/nts/ basisprincipes-nts/

23. Field A. Discovering statistics using SPSS. Sage Publication. 2009.

24. Van Der Linden C, Reijnen R, Derlet RW, et al. Emergency department crowding in the Netherlands: Managers' experiences. Int J Emerg Med 2013;6:41.

25. Erenler AK, Akbulut S, Guzel M, et al. Reasons for overcrowding in the emergency department: Experiences and suggestions of an education and research hospital. Turk J Emerg Med 2016;14:59-63.

26. Amina S, Barrati A, Sadeghifar J, et al. Measuring and analyzing waiting time indicators of patients' admitted in emergency department: a case study. Glob J Health Sci 2015;8:143-9.

27. Cooke MW, Wilson S, Halsall J, Roalfe A. Total time in English accident and emergency departments is related to bed occupancy. Emerg Med J 2004;21:575-6.

28. Forster AJ, Stiell I, Wells G, et al. The effect of hospital occupancy on emergency department length of stay and patient disposition. Acad Emerg Med 2003;10:127-33.

29. CDC. Who is at high risk for flu complications? [Internet] Centers for Disease Control and Prevention. 2017 [cited 2020 June 18]. Available from: https://www.cdc.gov/ flu/highrisk/ index.htm

30. Bucheli B, Martina B. Reduced length of stay in medical emergency department patients: a prospective controlled study on emergency physician staffing. Eur J Emerg Med 2004;11:2934. 